\title{
Contribution to Load-Frequency Regulation of a Hydropower Plant with Long Tail-Race Tunnel
}

\author{
Guillermo Martínez-Lucas, José Ignacio Sarasúa, José Román Wilhelmi, José Ángel Sánchez
}

\begin{abstract}
In this paper, a hydroelectric power plant with long tail-race tunnel has been modelled for assessing its contribution to secondary regulation reserve. Cavitation problems, caused by the discharge conduit length, are expected downstream the turbine where low pressure appears during regulation manoeuvres. Therefore, governor's gains should be selected taking into account these phenomena. On the other hand, regulation services bidden by the plant operator should fulfil TSO (Transmission System Operator) quality requirements. A methodology for tuning governor PI gains is proposed and applied to a Hydro power plant in pre-design phase in northwest area of Spain. The PI gains adjustment proposed provides a proper plant response, according to some established indexes, while avoiding cavitation phenomena.
\end{abstract}

Keywords-hydropower generation; load-frequency control; long tail-race; cavitation

\section{NOMENCLATURE}

$A C E$
$a_{d}$
$A T$
$A_{t}$
$D$
$D_{p s}$

Area control error

Wave speed $(\mathrm{m} / \mathrm{s})$ in tail-race

Threshold limit error

Turbine parameter

Turbine parameter

Load-frequency sensitivity (p.u.)

Error Difference between generated power and power required by $\mathrm{TSO}$

error $_{A G C} \quad A G C$ error index

$F_{d} \quad$ Tail-race tunnel section $\left(\mathrm{m}^{2}\right)$

$F_{p} \quad$ Penstock section $\left(\mathrm{m}^{2}\right)$

$g \quad$ Gravity acceleration $\left(\mathrm{m} / \mathrm{s}^{2}\right)$

H Net head (m.w.c.)

h Net head (p.u.)

$H_{b} \quad$ Base head (m)

$H_{b a} \quad$ Barometric pressure head (m.w.c.)

$h_{c} \quad$ Reservoir water level (p.u.)

$h_{d} \quad$ Discharge water level (p.u.)

$h_{p} \quad$ Head upstream of the turbine (p.u.)

$H_{s} \quad$ Suction head at the turbine outlet (m.w.c.)

$h_{t} \quad$ Head downstream of the turbine (p.u.)

$H_{t} \quad$ Head downstream of the turbine (m.w.c.)

$H_{t}(s) \quad$ Head downstream of the turbine in frequency domain (p.u.)

The work presented in the paper has been partially funded by the Spanish Ministry of Economy and Competitiveness under the project "Optimal operation and control of pumped-storage hydropower plants" of The National Scientific Research, Development and Technological Innovation Plan 20082011 (Ref. ENE2012-32207)

\begin{tabular}{|c|c|}
\hline$H_{t, m i n}$ & $\begin{array}{l}\text { Minimum high pressure downstream of the } \\
\text { turbine (m.w.c.) }\end{array}$ \\
\hline$k$ & $\begin{array}{l}\text { Number of cycles in which the AGC signal is } \\
\text { divided }\end{array}$ \\
\hline$K_{I}$ & Integral gain in PI governor \\
\hline$K_{p}$ & Proportional gain in PI governor \\
\hline$k_{p s}$ & External system frequency characteristic (p.u.) \\
\hline$K_{p s}$ & Frequency characteristic $(\mathrm{MW} / \mathrm{Hz})$ \\
\hline$L_{d}$ & Tail-race tunnel length (m) \\
\hline$L_{p}$ & Penstock length $(\mathrm{m})$ \\
\hline$n$ & Frequency (p.u.) \\
\hline$n_{\text {ref }}$ & Reference frequency (p.u.) \\
\hline$N_{s}$ & Specific speed of the turbine (r.p.m.) \\
\hline$P_{b}^{0}$ & Base power $(\mathrm{MW})$ \\
\hline$p_{\mathcal{R}}$ & Generated power (p.u.) \\
\hline$q$ & Flow through the turbine (p.u.) \\
\hline$Q_{b}$ & Base flow $\left(\mathrm{m}^{3} / \mathrm{s}\right)$ \\
\hline & Flow at the tail-race tunnel upstream end (p.u.) \\
\hline$Q_{d}(s)$ & $\begin{array}{l}\text { Flow at the tail-race tunnel upstream end in } \\
\text { frequency domain (p.u.) }\end{array}$ \\
\hline$q_{n l}$ & No-load flow (p.u.) \\
\hline$q_{p}$ & Flow at the penstock (p.u.) \\
\hline$r_{d} / 2$ & $\begin{array}{l}\text { Continuous head loses coefficient in tail-race } \\
\text { tunnel (p.u.) }\end{array}$ \\
\hline$r_{p} / 2$ & $\begin{array}{l}\text { Continuous head loses coefficient in penstock } \\
\text { (p.u.) }\end{array}$ \\
\hline$T_{e d}$ & $=L_{d} / a_{d}$. Tail-race tunnel water elastic time $(\mathrm{s})$ \\
\hline$T_{m}$ & Generator mechanical starting time (s) \\
\hline$T_{p s}$ & External system mechanical starting time (s) \\
\hline$T_{r}$ & Dashpot time constant (s) \\
\hline$T_{w d}$ & Tail-race tunnel water starting time (s) \\
\hline$T_{w p}$ & Penstock water starting time $(\mathrm{s})$ \\
\hline$z$ & Wicket gate opening (p.u.) \\
\hline$\delta$ & Temporary speed droop \\
\hline$\sigma$ & Permanent speed droop \\
\hline$\sigma^{\prime}$ & Thoma cavitation factor \\
\hline$\sigma_{c}$ & Critical cavitation factor \\
\hline$\sigma_{R}$ & $\mathrm{~K}$-factor of the control area (p.u.) \\
\hline$\omega_{b}$ & Base system frequency $(\mathrm{rd} / \mathrm{s})$ \\
\hline 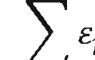 & Power mean square error, MSE (p.u.) \\
\hline
\end{tabular}




\section{INTRODUCTION}

Load-Frequency regulation is one of the ancillary services of a power system. Unpredictable changes in the load demand occur continuously in interconnected power system. These load changes always cause a mismatch between power generation and consumption, thus introducing deviations in frequency and in scheduled tie-line power [1]. The objective of load - frequency regulation is to maintain the system frequency and power interchanges at their scheduled values, changing power generation so that the equilibrium between generation and demand is achieved. The European Union policy has considerably encouraged the development of renewable resources in response to environmental concerns; however, their unpredictable and intermittent characteristics have restrained their deployment because of the negative impact on power system security, stability, reliability and efficiency [2]. This is one of the reasons for the increase in installed capacity of pumped-storage power plants providing large storage capacity [3]. In general, pumped-storage power plants have a fast and flexible response, so they can contribute efficiently to the needs of system regulation [4]. In some cases, the new sites available for building these power plants require long hydraulic conduits due to geographic, environmental or economic constraints (higher slopes are in general advantageous). Some of the technical problems associated with long pipes are connected with elastic phenomena, especially in those cases where for economic and environmental constraints no surge tank is built. This circumstance limits the applicability of the rigid-water-column models [5]. In long discharge pipes, cavitation phenomena may appear downstream of the turbine due to an excessive suction pressure caused by gate closing movements [6]

In Spain, the load-frequency regulation system is implemented in three different control loops, primary, secondary and tertiary, each one operating in different time scales. Power systems are usually organized into control areas, each one with its own generation and demand and with scheduled power interchanges between them. The purpose of the secondary regulation loop, usually known as automatic generation control (AGC), is to keep both the system frequency and the power interchanges at their scheduled values [7]. In order to provide the regulation services, power plants must adapt their operating point and vary the power output within very short time frames, in accordance with the requirements of the electric power system operator, In [8] changes in generated power of $25 \mathrm{MW} / \mathrm{s}$ are described, which involve gate opening or closing in $12 \mathrm{~s}$.

For this reason, the power plant dynamic response to load variations of different magnitudes should be studied in detail, in order to guarantee the capability of the power plant for providing said reserves within the required response times, avoiding harmful pressure fluctuations and instabilities [9]. To the author's knowledge, the combination of all these aspects has not been previously discussed in the literature

In this paper, the dynamic response of a hydroelectric plant sited in the Spanish Northwest, currently in design phase, is studied. The plant has a discharge pipe long enough to give rise to low pressure downstream of the turbine; so it is necessary to consider the influence of elastic phenomena. The plant owner is evaluating the feasibility of a design without surge tank and its consequences in the load-frequency control. In this sense, it is necessary to find the gains of a PI controller providing the greatest regulation band, while keeping the pressure downstream the turbine within operating limits. For this purpose a continuous elastic nonlinear model is used. The power plant is supposed to operate within a control area of an interconnected system, participating in secondary regulation. Therefore, it is also studied the possible interaction between the signals sent by the AGC and the pressure waves in the tailrace. An exhaustive search of the parameters of PI controller that does not compromise the safety of pipelines, avoiding cavitation, has been performed.

The paper is organized as follows. In section II the hydro plant dynamic model is described. In section III the cavitation phenomena is analyzed and a tuning criterion is proposed taking cavitation into account, comparing it with classical adjustment criteria. In section IV the simulated dynamic response of the plant under study with the proposed adjustment is shown. Finally, in section V, main conclusions of the paper are duly drawn.

\section{Plant Dynamic MODEL}

Hydropower plant mathematical model has been developed by using Matlab Simulink. The block diagram of the considered system is represented in Fig. 1. The equations associated with the block diagrams shown in Fig. 1, all expressed in per unit values, are detailed in the following sections.

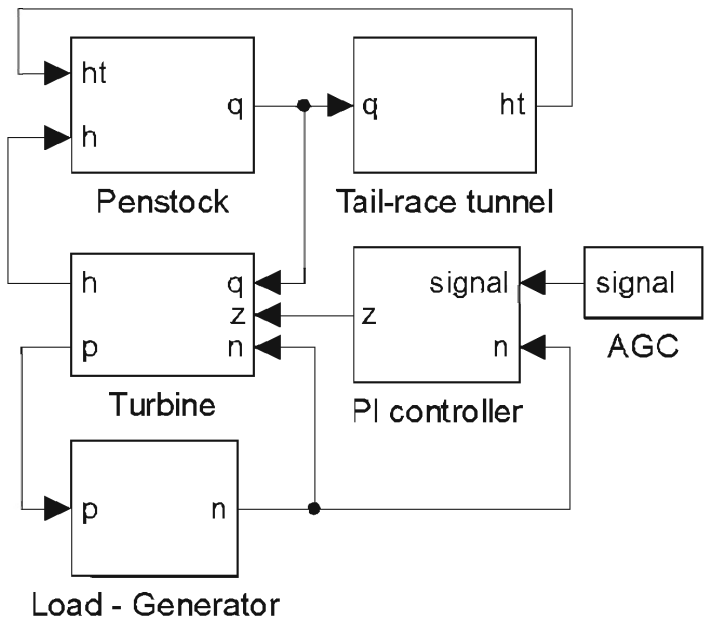

Fig. 1, Block diagram of the plant model

\section{A. Conduits}

Penstock is modelled assuming a rigid water column approach according to its short length [10-11]. The penstock dynamics is formulated in equation (1). 


$$
\frac{d q_{p}}{d t}=\frac{1}{T_{w p}}\left(h_{c}-h_{p}-\frac{r_{p}}{2} \cdot q_{p} \cdot\left|q_{p}\right|\right)
$$

where $T_{w p}$ is the water starting time in the penstock, defined in (2):

$$
T_{w p}=\frac{L_{p}}{g F_{P}} \frac{Q_{b}}{H_{b}}
$$

The length of the tail-race tunnel makes necessary to consider the elasticity of water and conduit; the expression (3) gives the upstream flow-head transfer function for constant head at downstream end.

$$
\frac{\Delta H_{t}(s)}{\Delta Q_{d}(s)}=-\frac{T_{w d} \frac{a_{d}}{L_{d}}\left(1-e^{-2 \frac{L_{d}}{a_{d}} s}\right)}{1+e^{-2 \frac{L_{d}}{a_{d}} s}}
$$

For the sake of accuracy the head losses, $\left(r_{d} / 2\right)$, are included as shown in Fig. 2 [11]. The head downstream the turbine $h_{t}$, is obtained from the lower reservoir water level $h_{d}$, considering the friction losses $r_{d}$ and the pressure waves contribution.

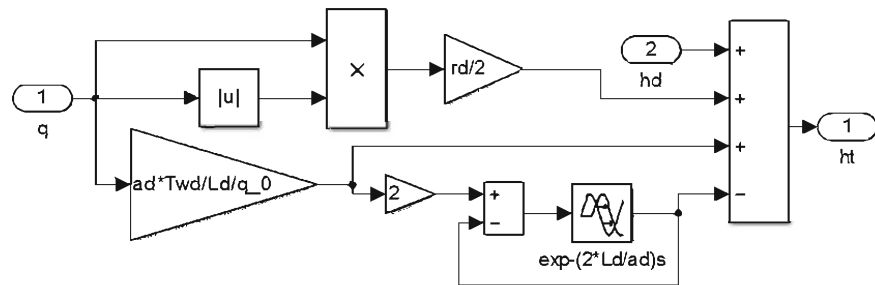

Fig. 2: Block diagram of tail race

The net head is given by equation (4); in Fig. 3 the energy line is shown.

$$
h=h_{p}-h_{t}
$$

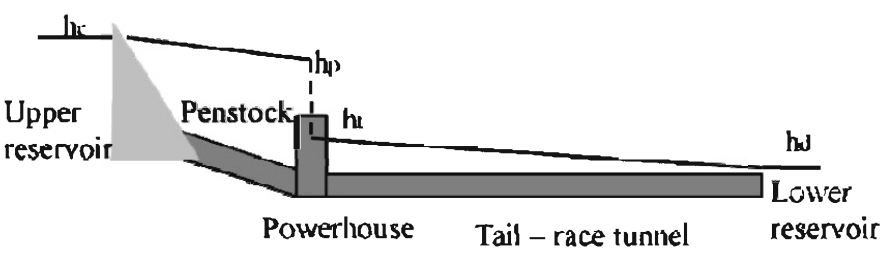

Fig. 3, Plant scheme

Areas of upper and lower reservoirs are large enough so that water levels can be supposed to be constant during simulations.

\section{B. Turbine}

The pump-turbine is modelled according to expressions (5, 6), following the widely used recommendations of the IEEE WG [11]

$$
\begin{gathered}
q=z \sqrt{h} \\
p_{g}=A_{t} h\left(q-q_{n l}\right)-D z \Delta n
\end{gathered}
$$

The modelled power plant may have two or more identical units, which are supposed to work at the same operating point; thus a single equivalent turbine has been considered.

\section{Generation - load}

An inertial model, adapted from [12], has been used for modelling the frequency transients in control area, $(7,8)$ :

$$
p_{g}-p_{d}-k_{p s} \Delta n=\left(T_{m}+T_{p s}\right) n \frac{d n}{d t}
$$

where

$$
k_{p s}=K_{p s} \frac{\omega_{b} / 2 \pi}{P_{b}}+D_{p s} \text { and } \quad D_{p s}=\frac{\partial p_{d}}{\partial n}
$$

\section{Governor}

A conventional proportional-integral (PI) controller processes the frequency error signal $\left(n_{\text {ref }}-n\right)-\sigma z$. Equation (9) gives the changes in the gate position due to the controller action [13].

$$
z=\left[\frac{1}{\delta}+\frac{1}{\delta T_{r}} \int d t\right]\left[\left(n_{r e f}-n\right)-\sigma z\right]
$$

The PI gains are:

$$
K_{P}=\frac{1}{\delta} \text { and } K_{l}=\frac{1}{\delta T_{r}}
$$

As it is shown in Fig. 4, a speed limiter in the gate position movements ( \pm 0.1 p.u.), has been considered.

\section{CONTROLLER PARAMETERS TUNING}

Power systems are usually organized into control areas, each one with its own generation and demand and with scheduled power interchanges between them. The purpose of the secondary regulation loop, usually known as automatic generation control (AGC), is to keep both the system frequency and the power interchanges at their scheduled values.

The model described in previous section will be supposed to have one single input: the power signal provided by the AGC, as shown in Fig. 4. No load variations inside the control area will be considered.

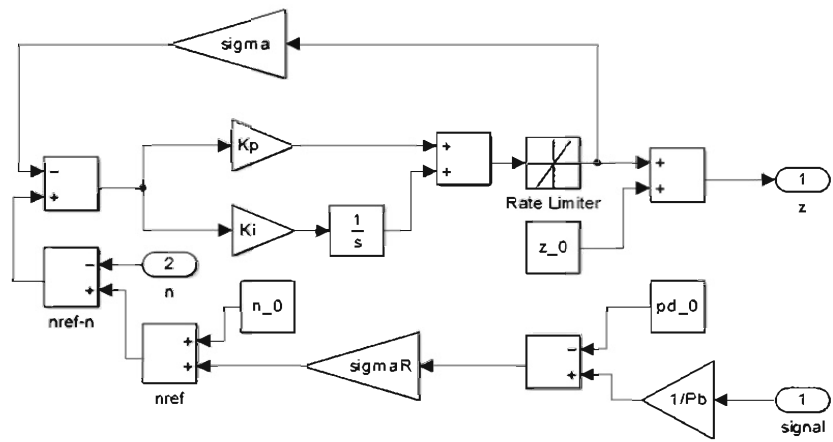

Fig. 4, Block diagram of PI controller in interconnected system 


\section{A. Reference power plant}

The set of parameters that define the hydroelectric power plant and the external system are shown in Table 1.

\begin{tabular}{llllll}
\multicolumn{5}{c}{ TABLE 1.PLANT AND SYSTEM PARAMETERS } \\
\hline$Q_{b}$ & $180 \mathrm{~m}^{3} / \mathrm{s}$ & $H_{b}$ & $135.09 \mathrm{~m}$ & $P_{b}$ & $214 \mathrm{MW}$ \\
$T_{w p}$ & $1.4505 \mathrm{~s}$ & $T_{w d}$ & $6.4110 \mathrm{~s}$ & $T_{e d}$ & $2.03 \mathrm{~s}$ \\
$r_{p} / 2$ & 0.0128 & $r_{d} / 2$ & 0.0778 & $\sigma=\sigma_{R}$ & 0.03 \\
$T_{m}$ & $6 \mathrm{~s}$ & $T_{p s}$ & $364.49 \mathrm{~s}$ & $k_{p s}$ & 1012.5 \\
\hline
\end{tabular}

\section{B. Hydraulic limitations}

The main hydraulic problem which may appear in power plants with long discharge conduits is cavitation. The critical area where this phenomenon is especially damaging is that located downstream the turbine. Therefore, the proposed PI tuning should be appropriate to avoid this limitation.

Firstly, it is necessary to find the minimum threshold of pressure that guarantees no cavitation. Prof. D. Thoma suggested a dimensionless number, called Thoma's cavitation factor, $\sigma$ ', which can be used for determining the region where cavitation take place in reaction turbines [14]:

$$
\sigma^{\prime}=\frac{H_{b a}-H_{s}}{H}
$$

The value of Thoma's cavitation factor $\left(\sigma^{\prime}\right)$ is compared with critical cavitation factor $\left(\sigma_{c}\right)$. This factor depends on the type of turbine. If the value of $\sigma^{\prime}$ is greater than $\sigma_{c}$ cavitation will not occur in that turbine. For Francis turbines, the cavitation critical factor is (12):

$$
\sigma_{c}=431 \times 10^{-8} \times N_{s}^{2}
$$

Therefore, the height of minimum pressure is obtained $-H_{s}=H_{t}>-7.5$ meters of water column (m.w.c.).

\section{Regulatory services}

The Transmission system operator (TSO) requires energy producers to fulfil service requirements. The power plant response must be quick enough or power plant's owner would be penalised. On the other hand extremely fast responses may not be necessary and would surely be harmful for mechanical power plant devices.

In [15] an index to assess if the regulation area complies with response criteria imposed by the TSO is proposed. Moreover, this index penalizes excessively fast responses, so it is suitable for the problem analysed in this paper; therefore it will be applied to the reference power plant in next sections.

\section{Proposed methodology}

In order to study the power plant response providing loadfrequency regulation, a real AGC signal has been adapted to the installed power capacity Fig. 5. It is supposed that the maximum regulation band has been bidden, the initial generated power being adjusted at 0.75 p.u., which is lying between rated power and minimum feasible power, 0.50 p.u.

System response to AGC signal has been simulated changing PI gains, performing an exhaustive search. $T_{r}$ values have ranged from 0.2 to 5 and $K_{p}$ have ranged from 0.2 to 10 in steps of 0.2 in both cases. The minimum pressure downstream of the turbine, $H_{t, m i n}$ has been obtained for each pair of setting values. Power mean square error, $\overline{\sum \varepsilon_{p}{ }^{2}}$ was also calculated.

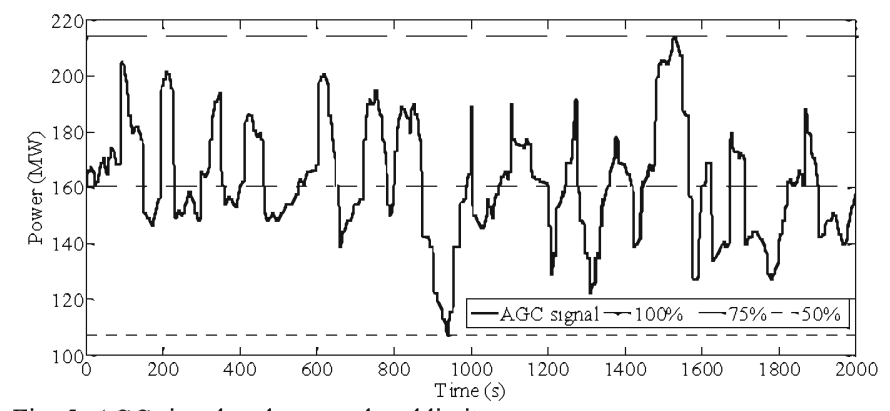

Fig. 5, AGC signal and reserve band limits

The pairs of gains providing greater pressure downstream of the turbine, correspond to the lower values of $K_{p}$ and the higher of $T_{r}$. These governor adjustments correspond to a greater power mean square error because the weakness of the control action.

The region of values pairs that provide a lower mean square error (higher $K_{p}$ and lower $T_{r}$ ) correspond to a lower pressure downstream of the turbine (cavitation phenomena). These pairs of gains result more strong.

Therefore, a series of pairs of gains has been obtained that meet the condition of minimum height to avoid cavitation, $\mathrm{H}_{t}>-7.5$ m.w.c., giving rise to a minimum power mean square error. This set of parameters defines, approximately, a line, (Fig. 6), given by the following expression (13).

$$
K_{p} \cong 2.1607 T_{r}+0.3295
$$

Failure rate proposed in [15], as expressed by equation (14), is used to evaluate the percentage of cycles in which the magnitude error $A G C$ is greater than the threshold (in this case $7 \%$ of the total regulation band). This index shows, for a certain period of time, the percentage of cycles in which the power plant fails to comply TSO requirements.

$$
\begin{gathered}
\operatorname{error}_{A G C}=\frac{\sum_{k=1 \cdot}^{N}[A C E(k)]}{N} \\
A C E(k)= \begin{cases}1 & \mid \text { Error } \mid>A T(k) \\
0 & \mid \text { Error } \mid \leq A T(k)\end{cases}
\end{gathered}
$$

The response to the $\mathrm{AGC}$ signal is simulated again for different pairs of gains that fulfil expression (13). The magnitude error ${ }_{A G C}$ is obtained and plotted in Fig. 6. The selected pair of gains satisfies the condition (13) and corresponds to the minimum value of error $_{A G C}$. The setting values, the error ${ }_{A G C}$ and pressure height downstream the turbine are shown in Table 2. Results obtained applying classical PI tuning criteria are also shown in the table for comparison purposes. Any PI tuning criteria has been found by the authors in the literature taking into account low pressure downstream the turbine due to the tail-race tunnel length. 
TABLE 2, REFERENCE HYDROPOWER PLANT PI GAINS, ERRO $R_{A G C}$, POWER MEAN SQUARE ERROR AND WATER PRESSURE DOWNSTREAM TURBINE $\mathrm{H}_{7}$

\begin{tabular}{llllll}
\hline Criterion & $K_{p}$ & $T_{r}$ & error $_{A G C}$ & $M S E$ & $H_{t, m i n}$ \\
Paynter [16] & 0.31 & 39.31 & $10.78 \%$ & 406.17 & 5.87 \\
Kundur[17] & 0.60 & 12.34 & $8.18 \%$ & 402.38 & 5.60 \\
Proposed & 5.20 & 2.20 & $5.99 \%$ & 290.75 & -7.45
\end{tabular}

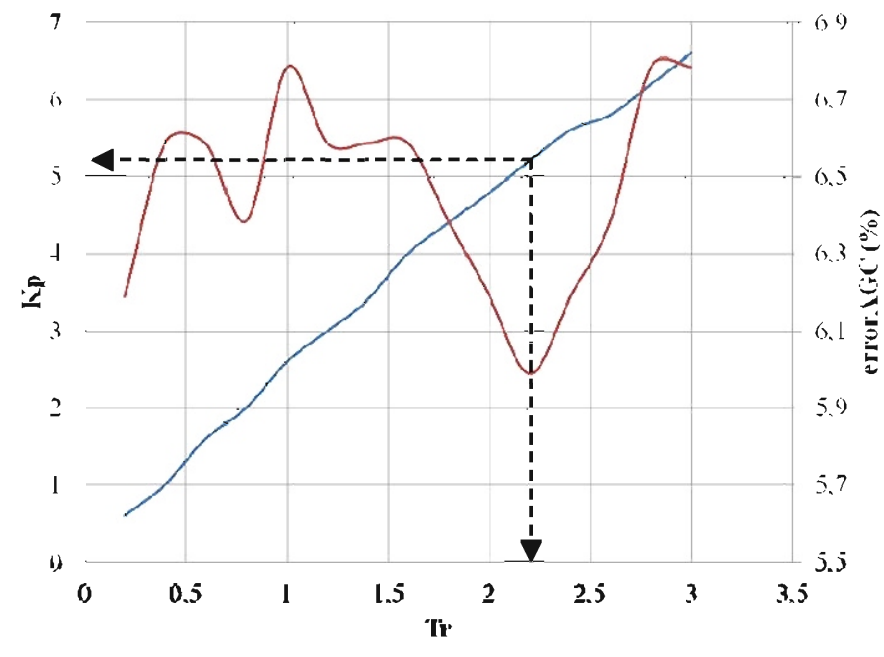

-ili_min--7.5 m.c.n. - error $\lambda$ sic:

Fig. 6, Set of gains that prevents cavitation (blue line) and error ${ }_{A G C}$ for each pair of gains (red line)

\section{RESULTS}

Assuming the setting shown in Table 2 the response of the plant is shown in Fig. 7. It is verified that the pressure height downstream the turbine does not reach a value lower than the minimum required for preventing the cavitation phenomenon.

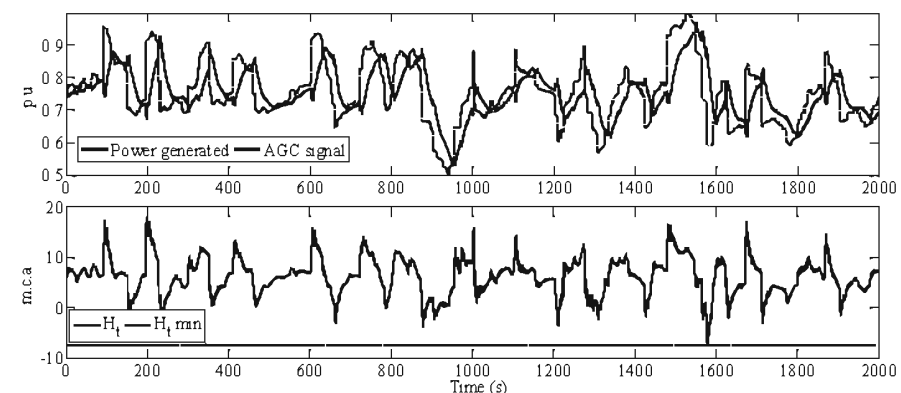

Fig. 7, Hydro plant dynamic response with AGC signal.

\section{CONCLUSIONS}

In this paper, the contribution of a hydroelectric power plant having long tail-race tunnel to secondary regulation has been assessed. A dynamic model of a plant of these characteristics without surge tank has been successfully used for this purpose.

An exhaustive search of the parameters of a PI controller that does not compromise the safety of pipelines, avoiding cavitation, has been performed.

It has been verified that TSO requirements can be satisfied for appropriate PI adjustment, avoiding an excessively fast response that could result in damages for some mechanical components.

The results confirm the adequacy of the plant design without surge tank for secondary regulation while keeping hydraulic pressures downstream the turbine within operating limits.

\section{ACKNOWLEDGMENTS}

Authors wish to thank the working groups from GAS NATURAL FENOSA and IBERDROLA for their valuable help in the development of the study presented in this paper.

\section{REFERENCES}

E. Hamedrahmat and A. Yazdizadeh, "Decentralized Self-Tuning Pole Placement Controller for Load Frequency Control in KHOZESTAN Area," in 18th IEEE International Conference on Control Applications, Saint Petersburg, Russia, 2009.

G. Ardizzon, G. Cavazzini and G. Pavesi, "A new generation of small hydro and pumped - hydro power plants: Advances and future challenges," Renewable and Sustainable Energy Reviews, no. 31, pp. 746-761, 2014.

IDAE. Ministerio de Industria, Energía y Turismo, "Plan de energías Renovables 2011-2020," Madrid, 2011.

C.-J. Yang and R. Jackson, "Opportunities and barriers to pumpedhydro energy storage in the United States," Renewable and Su stainable Energy Reviews, vol. 15, no. 1, pp. 839-844, 2011.

O. F. Jiménez and M. Chaudhry, "Stability Limits of Hydroelectric Power Plants," Journal of energy Engineering, vol. 113, no. 2, pp. 50$60,1987$.

U. Dorji and R. Ghomashchi, "Hydro turbine failure mechanisms: An overview," Engineering Failure Analysis, vol. 44, pp. 136-147, 2014.

I. Egido, F. Fernández-Bernal and L. Rouco, "The Spanish AGC System: Description and Analysis," IEEE Transactions on Power Systems, vol. 24, no. 1, pp. 271-278, 2009.

G. Muñoz-Hernández and D. Jones, "Simulation studies of a GPC controller for a hydroelectric plant," Transactions of the Institute of Measurement and Control, vol. 29, no. 1, pp. 35-51, 2007.

J. I. Pérez-Díaz, J. R. Wilhelmi Ayza, I. Galaso Bajo, J. Fraile-Ardanuy, J. Á. Sánchez Fernandez, O. Castaneda Cabrero and J. I. Sarasúa Moreno, "Dynamic response of hydro power plants to load variations for providing secondary regulation reserves considering elastic water column effects," Przeglad Elektrotechniczny, vol. 88, no. 1A, pp. 159$163,2012$.

M. H. Chaudhry, "Governing stability of a hydroelectric power plant," Water Power, pp. 131-136, 1970.

IEEE Working Group, "Hydraulic turbine and turbine control models for system dynamic studies," IEEE Transactions on Power Systems, vol. 7 , no. 1, pp. 167-179, 1992 .

S. Mansoor, D. Jones, F. Bradley and G. Jones, "Reproducing oscillatory behaviour of a hydroelectric power station by computer simulation," Control Engineering Practice, vol. 8, no. 11, pp. 1261 1272,2000

C. Sanathanan, "Accurate low order model for hydraulic turbinepenstock," IEEE Transactions on energy Conversion, vol. 2, no. 2, pp. 196-200, 1987. 
P. Kumar and R. Saini, "Study of cavitation in hydro turbines - A review," Renewable and Sustainable Energy Reviews, no. 14, pp. 37433, 2010.

I. Egido, F. Fernández-Bernal and L. Rouco, "Evaluatión of Automatic Generation Control (AGC) regulators by performance indices using data from real operation," Generation, Transmission \& Distribution, IET, vol. 1, no. 2, pp. 294-302, 2007.

H. Paynter, A Palimpsest on the Electronic Analogue Art, Boston: Philbrik Researches Inc, 1955.

P. Kundur, Power system stability and control, New York (USA): Mc Graw Hill, 1994. 